\title{
Association of outdoor temperature with lung function in a temperate climate
}

\author{
Mary B. Rice $\mathbb{0}^{1}$, Wenyuan Li $\mathbb{B}^{2}$, Elissa H. Wilker², Diane R. Gold², \\ Joel Schwartz ${ }^{2}$, Antonella Zanobetti ${ }^{2}$, Petros Koutrakis², Itai Kloog ${ }^{3}$, \\ George R. Washko ${ }^{4,5}$, George T. O'Connor ${ }^{5,6}$ and Murray A. Mittleman ${ }^{2}$ \\ Affiliations: ${ }^{1}$ Division of Pulmonary, Critical Care and Sleep Medicine, Dept of Medicine, Beth Israel \\ Deaconess Medical Center, Harvard Medical School, Boston, MA, USA. ${ }^{2}$ Harvard T.H. Chan School of Public \\ Health, Boston, MA, USA. ${ }^{3}$ Dept of Geography and Environmental Development, Ben-Gurion University of the \\ Negev, Beer Sheva, Israel. "'Division of Pulmonary and Critical Care Medicine, Dept of Medicine, Brigham and \\ Women's Hospital, Boston, MA, USA. ${ }^{5}$ The NHLBI's Framingham Heart Study, Framingham, MA, USA. \\ ${ }^{6}$ Pulmonary Center, Dept of Medicine, Boston University School of Medicine, Boston, MA, USA.
}

Correspondence: Mary B. Rice, Division of Pulmonary, Critical Care and Sleep Medicine, Beth Israel Deaconess Medical Center, 330 Brookline Avenue, Boston, MA 02215, USA.

E-mail: mrice1abidmc.harvard.edu

@ERSpublications

A higher temperature in the preceding days is associated with lower lung function, especially during the spring and winter but not in summer. These findings may be explained by more time spent outdoors on warmer days in a temperate climate. http://ow.ly/MwIE30msEWk

Cite this article as: Rice $\mathrm{MB}, \mathrm{Li} \mathrm{W}$, Wilker $\mathrm{EH}$, et al. Association of outdoor temperature with lung function in a temperate climate. Eur Respir J 2019; 53: 1800612 [https://doi.org/10.1183/13993003.006122018].

ABSTRACT Acute exposure to cold dry air is a trigger of bronchoconstriction, but little is known about how daily outdoor temperature influences lung function.

We investigated associations of temperature from a model using satellite remote sensing data with repeated measures of lung function among 5896 participants of the Framingham Heart Study Offspring and Third Generation cohorts residing in the Northeastern US. We further tested if temperature modified previously reported associations between pollution and lung function. We constructed linear mixed-effects models, and assessed departures from linearity using penalised splines.

In fully adjusted linear models, 1-, 2- and 7-day average temperatures were all associated with lower lung function: each $5^{\circ} \mathrm{C}$ higher previous-week temperature was associated with a $20 \mathrm{~mL}$ lower $(95 \% \mathrm{CI}$ $-34--6)$ forced expiratory volume in $1 \mathrm{~s}$. There was significant effect modification by season: negative associations of temperature and lung function were present in winter and spring only. Negative associations between previous-day fine particulate matter and lung function were present during unseasonably warm but not unseasonably cool days, with a similar pattern for other pollutants.

We speculate that temperature-related differences in lung function may be explained by behavioural changes on relatively warm days, which may increase outdoor exposures. 


\section{Introduction}

Climate change is increasing the magnitude of forest fire air pollution, heat-related ozone pollution, pollen production and other environmental exposures that are known to be harmful to respiratory health $[1,2]$. As average temperatures rise, there is a need to quantify relationships between weather conditions and respiratory health. Cold and hot weather are both associated with more hospital visits for respiratory disease, with most studies in temperate climates finding U- or J-shaped relationships between temperature and respiratory hospitalisations [3-6]. Controlled human exposure studies provide evidence of transient increases in airway resistance after brief periods of intense exposure to cold [7], and also to heat, especially among people with asthma [7-9], but these studies do not mimic real-world daily exposure to outdoor weather conditions. Recent studies of elderly men and people with asthma have found that warmer temperatures are associated with lower lung function $[10,11]$, but it is unclear if the general population experiences differences in lung function in association with average outdoor temperature. Studies examining residence-specific temperature and lung function are lacking.

There is also little understanding of whether outdoor temperature modifies the known respiratory effects of exposure to air pollutants. A large number of studies, including prior work in the Framingham Heart Study, have found that higher levels of outdoor air pollutants, including fine particulate matter (particles with a diameter of $<2.5 \mu \mathrm{m}(\mathrm{PM} 2.5))$ and ozone $\left(\mathrm{O}_{3}\right)$, are associated with lower lung function [12-14]. One study of healthy individuals in China found that associations between PM2.5 exposure and forced expiratory volume in $1 \mathrm{~s}$ (FEV1) were larger in the setting of higher temperatures [15], and a recent study of elderly men in the Northeastern US also found an interaction between warmer temperature and black carbon (a constituent of PM2.5) and lower lung function [10]. Studies of mortality have suggested that the mortality effects of air pollution, including $\mathrm{PM} 2.5$ and $\mathrm{O}_{3}$, are greater in the setting of warmer temperatures [16-18]. However, despite the wealth of evidence that air pollution affects lung function, and evidence of higher respiratory hospitalisation at the extremes of temperature, interactions between outdoor temperature and pollution on lung function remain largely unexplored.

We estimated daily outdoor temperature at the home address among participants of the Offspring and Third Generation Cohorts of the Framingham Heart Study residing in the Northeastern US with a novel, validated spatiotemporal temperature model using satellite-based surface temperature measurements [ 19 , 20]. We hypothesised that colder and warmer outdoor temperature would be associated with lower lung function in a non-linear pattern and, based on published findings of the relationship between temperature and mortality [21], that the magnitude of the effects of temperature on lung function would vary by season, owing to physiologic adaptation. We further hypothesised that the associations between outdoor pollution and lung function that we previously reported in this cohort [12] would be greater in the setting of warmer outdoor temperatures.

\section{Methods \\ Study population}

The study population consisted of the participants in the Framingham Heart Study Offspring and Third Generation cohorts living within the Northeastern US, including New England (Massachusetts, New Hampshire, Rhode Island, Maine) and the Tri-State area (New York, New Jersey, Connecticut). The design of these studies has previously been described $[22,23]$. Offspring participants with at least one spirometry measurement after the year 2000 (when satellite-based estimates of temperature became available) at examination $7(2000-2001)$ or $8(2005-2008)$ and Third Generation participants with at least one measurement at examination $1(2002-2005)$ or $2(2008-2011)$ were included. The proportion of participants completing spirometry was $72 \%$ and $85 \%$ at Offspring examinations 7 and 8 , and $94 \%$ and $95 \%$ at Third Generation examinations 1 and 2. At each examination, data were collected on demographics, medication use, smoking history and respiratory symptoms and diagnoses. There were 5896 participants with temperature data at their home address, providing 9150 spirometry measurements in our primary analysis. All participants provided written informed consent for the study examinations, and the institutional review boards of Beth Israel Deaconess Medical Center and Boston University Medical Campus approved this work.

\section{Temperature exposure}

We assigned daily temperature at the home address to each participant with a prediction model that uses satellite surface temperature data to estimate daily ambient air temperature, beginning in the year 2000 . A mixed-model approach was used to calibrate daily satellite surface temperature obtained from the Moderate Resolution Imaging Spectroradiometer satellite (Terra) at $1 \times 1 \mathrm{~km}$ resolution against air temperature values obtained from the National Climatic Data Center, Environmental Protection Agency (EPA) and Weather Underground Inc., as previously described [24]. Air temperature predictors (per cent urban, elevation, normalised difference vegetation index) and a random intercept and random slope were 
used to calibrate the model for each day. Because surface temperature values from the satellite are often missing owing to cloud cover or retrieval errors, an additional model was fit that took advantage of the association of grid cells' surface temperature values with air temperature monitoring located elsewhere, and the association with surface temperature values in neighbouring grid cells. Out-of-sample "ten-fold" cross-validation was used to quantify the accuracy of the model's temperature predictions [24]. Model performance was excellent for days both with and without available satellite data (mean out-of-sample $\mathrm{R}^{2}=0.947$ and $\mathrm{R}^{2}=0.940$, respectively).

Using these model predictions for each participant's geocoded home address, we calculated average temperature for the 1-, 2- and 7-day average of temperature including the day of the spirometry test, based on our a priori hypothesis that short-term temperature exposure would have the strongest associations with lung function. Hourly relative humidity data were obtained from the Boston Airport weather station (12 km from the central air pollution monitoring site).

\section{Air pollution exposure}

We used hourly PM2.5 concentration data from the Harvard Boston Supersite in Boston, MA, USA, five stories above ground level and $50 \mathrm{~m}$ from the nearest street. PM2.5 concentrations were measured using a tapered element oscillating microbalance (model 1400A; Rupprecht \& Pataschnick Co., Albany, NY, USA). The gaseous pollutants $\mathrm{O}_{3}$ and nitrogen dioxide $\left(\mathrm{NO}_{2}\right)$ were measured from state monitors in Eastern Massachusetts, and exposures were estimated by averaging data from available sites. By convention, $\mathrm{O}_{3}$ exposure was only examined during the EPA monitoring season for $\mathrm{O}_{3}$ in Massachusetts (April-September) [12, 25].

\section{Lung function measurement}

FEV1 and forced vital capacity (FVC) were measured at each examination by spirometry, with the spirometer calibrated daily at room temperature, barometric pressure and humidity. For Offspring examination 7, spirometry data were obtained using a Collins Survey II spirometer, interfaced to pulmonary function data acquisition and quality control software (S and M Instruments, Doylestown, PA, USA). For Offspring examination 8 and Third Generation examinations 1 and 2, spirometry data were obtained using a Collins CPL system (nSpire Health, Inc., Longmont, CO, USA). Spirometry manoeuvres were performed according to American Thoracic Society standards [26].

\section{Statistical analyses}

We selected covariates a priori based on known associations with lung function or temperature, and for consistency with prior publications $[12,27]$. Primary models adjusted for sex, age (as a linear and squared term), height, weight, smoking status, pack-years of smoking, any household smoking, current asthma, personal education, median household income from 2000 census tract, season, previous-day relative humidity, previous-day PM2.5, examination 8 and cohort. We defined current asthma as a report of wheeze in the past 12 months, or a current doctor diagnosis of asthma. We defined chronic obstructive pulmonary disease (COPD) based on a report of daily cough for at least three consecutive months of the year or a current diagnosis of chronic bronchitis, COPD or emphysema [12]. We used sine and cosine functions of the examination date to control for season. We assigned previous-day PM2.5 using the Harvard Supersite monitor as an indicator of regional particulate pollution, and did not adjust for $\mathrm{O}_{3}$ in our primary model because the monitors in Eastern Massachusetts may not reflect regional exposure. We did adjust for $\mathrm{O}_{3}$ in secondary analyses. We performed sensitivity analyses excluding Offspring examination 7 because the spirometry equipment changed after examination 7 .

We fit linear mixed-effects models with a subject-specific random intercept to examine associations of 1-, 2- and 7-day average of temperature with lung function (FEV1 and FVC), using PROC MIXED in SAS Version 9.4 (SAS Institute, Cary, NC, USA). We evaluated the linearity of each association by plotting generalised additive mixed models (GAMM) with penalised splines using R (R Foundation for Statistical Computing, Vienna, Austria). We tested if associations between temperature and lung function were modified by season or relative humidity. Seasons were defined as winter (December-February), spring (March-May), summer (June-August) and autumn (September-November). Based on evidence of differential susceptibility to temperature [9, 11, 28] and seasonal allergens such as pollen [29] among patients with asthma and people with COPD, we tested if associations with temperature differed by asthma and COPD status.

We evaluated if previous-day temperature at the home address modified associations between previous-day pollutant exposure $\left(\mathrm{PM} 2.5, \mathrm{NO}_{2}\right.$ and $\left.\mathrm{O}_{3}\right)$ and $\mathrm{FEV} 1$ in a subset of non-current smoking participants ( $\mathrm{n}=2051$ participants, 3076 observations) living within $40 \mathrm{~km}$ of the Harvard air pollution monitoring site, to reflect average exposures within the study region. The satellite-based estimates of temperature became available in the year 2000, and therefore this subset did not include observations from the 1990s that were 
included in our previous publication on acute respiratory effects of pollution ( $\mathrm{n}=3262,5358$ observations) [12]. For consistency with our prior work on acute respiratory effects of pollution within air quality standards [12], we included observations with previous-day pollution levels within $2013 \mathrm{EPA}$ air quality standards (only 21 observations had a 24-h PM2.5 level $>35 \mu \mathrm{g} \cdot \mathrm{m}^{-3}$, 37 observations had an 8 -h maximum $\mathrm{O}_{3}$ average $>75 \mathrm{ppb}$, and none had an hourly $\mathrm{NO}_{2}>100 \mathrm{ppb}$ ), and by convention we examined associations with $\mathrm{O}_{3}$ during the $\mathrm{O}_{3}$ monitoring season of Massachusetts (April-September). We assessed effect modification by previous-day temperature as a continuous variable and, in secondary analyses, in categories of relative temperature to determine if relatively warm or cold temperature (defined within the season) modified associations between pollution and lung function. Temperature within $1 \mathrm{SD}$ of the mean daily temperature for the season was defined as "seasonable", $>1$ SD above seasonal mean was defined as unseasonably "warm" and >1 sD below seasonal mean was defined as unseasonably "cool".

We used the Wald test for cross-product terms to determine the statistical significance of potential effect modifiers for continuous variables and the type 3 test of fixed effects to determine the significance of global interaction by categorical variables. A two-sided p-value of $<0.10$ was used to test for statistically significant effect modification.

\section{Results}

Participant characteristics for the 9150 observations are summarised in table 1. This is a middle- to older-aged cohort with a slight majority of women (54.2\%). Approximately half of observations included in the analysis were from never smokers and current smoking was rare (13\%). Nearly half of participants were college graduates and $74 \%$ completed at least some college. Asthma and wheeze were common: nearly one quarter of observations were from people with a diagnosis of asthma or wheeze in the past 12 months. Average lung function was normal.

Season-stratified mean temperature, humidity and pollutant levels the day preceding spirometry testing are provided in table 2. Temperature at the home address on the same date varied modestly across the

\section{TABLE 1 Characteristics of study participants}

\section{Characteristic}

Mean士sD or \%

$50.4 \pm 13.8$

45.8

$27.8 \pm 5.6$

34.9

$17.0 \pm 18.1$

$28.0 \pm 16.6$

49.4

37.1

13.4

25.4

21.2

31.6

46.8

$64.6 \pm 20.4$

23.1

4.7

22.8

26.4

25.4

25.4

$3.2 \pm 0.9$

$97.9 \pm 15.1$

$4.2 \pm 1.1$

$102.1 \pm 13.4$

Data calculated from 9150 observations lamong 5896 participants). BMI: body mass index; COPD: chronic obstructive pulmonary disease; FEV1: forced expiratory volume in $1 \mathrm{~s}$; FVC: forced vital capacity. 
TABLE 2 Home address temperature, air pollution and relative humidity on the day of the study visit, stratified by season

\begin{tabular}{|c|c|c|c|c|c|c|c|c|c|}
\hline & \multirow[t]{2}{*}{ Total observations $\mathbf{N}^{\#}$} & \multicolumn{2}{|c|}{ Winter } & \multicolumn{2}{|c|}{ Spring } & \multicolumn{2}{|c|}{ Summer } & \multicolumn{2}{|c|}{ Autumn } \\
\hline & & $\mathrm{n}$ & Mean士sd & $\mathbf{n}$ & Mean士sd & $\mathbf{n}$ & Mean士sD & $\mathbf{n}$ & Mean $\pm s D$ \\
\hline Temperature ${ }^{\circ} \mathrm{C}$ & 9150 & 2088 & $4.01 \pm 3.7$ & 2418 & $9.9 \pm 4.1$ & 2322 & $17.2 \pm 2.7$ & 2322 & $12.0 \pm 3.7$ \\
\hline $\mathrm{PM} 2.5 \mu \mathrm{g} \cdot \mathrm{m}^{-3}$ & 3047 & 727 & $8.8 \pm 4.3$ & 824 & $8.8 \pm 4.0$ & 767 & $11.5 \pm 6.5$ & 729 & $8.6 \pm 5.1$ \\
\hline $\mathrm{NO}_{2} \mathrm{ppb}^{\Uparrow}$ & 3076 & 727 & $21.8 \pm 7.3$ & 824 & $19.5 \pm 5.9$ & 789 & $17.0 \pm 5.0$ & 736 & $17.7 \pm 5.8$ \\
\hline $\mathrm{O}_{3} \mathrm{ppb}^{+}$ & 1550 & & & 546 & $30.6 \pm 8.7$ & 762 & $30.0 \pm 10.0$ & 242 & $19.7 \pm 6.8$ \\
\hline
\end{tabular}

$\mathrm{RH}$ : relative humidity; $\mathrm{PM} 2.5$ : particles with a diameter of $<2.5 \mu \mathrm{m} ; \mathrm{NO}_{2}$ : nitrogen dioxide; $\mathrm{O}_{3}$ : ozone. \# 9150 observations are reported from 5896 participants residing in the Northeastern US; ": air pollution data reported here is for nonsmoking participants living within $40 \mathrm{~km}$ of the Harvard Supersite Monitor in Boston with pollution levels within US Environmental Protection Agency (EPA) standards; ${ }^{+}$: ozone data is reported during the EPA ozone monitoring season for Massachusetts (April-September).

5896 unique participants ( $\mathrm{SD}<1^{\circ} \mathrm{C}$ for most sample dates tested). The geographic distribution of study participants' residences was concentrated around the state of Massachusetts, and extended to western New York and coastal Maine (supplementary figure S1).

The main associations of temperature with lung function are shown in table 3. Higher 1-, 2- and 7-day average temperatures were all associated with lower FEV1 and FVC. The penalised spline for the 2-day temperature average and FEV1 is shown in figure 1. The other splines appeared similar and are in the supplementary material. The splines demonstrate steeper negative associations of 1-, 2- and 7-day temperatures with $\mathrm{FEV}_{1}$ in the cooler temperature range $\left(<10^{\circ} \mathrm{C}\right)$, and a flattening of the association at warmer temperatures. Associations were unchanged with additional adjustment for previous-day $\mathrm{O}_{3}$ and in sensitivity analyses excluding observations from Offspring examination 7. Associations of temperature with FEV1 did not differ by relative humidity, or by asthma or COPD status (all $\mathrm{p}_{\text {interaction }}>0.1$ ) (supplementary table S1).

In linear mixed-effects models, there was evidence of effect modification by season for the associations of the 1-, 2- and 7-day temperature average with FEV1 (all $\mathrm{p}_{\text {interaction }}<0.05$ ). Figure 2 plots the results of a GAMM model with an interaction term by season for the 2-day average of temperature. There were negative linear associations between temperature and FEV1 in winter and spring, but not summer or autumn. In season-stratified linear models (table 4), associations between temperature and FEV 1 were more negative in winter and spring than for the overall sample and null in summer and autumn, except for the 7-day average of temperature in autumn, which was positively associated with FEV1.

Previous-day temperature did not modify associations between previous-day $\mathrm{PM} 2.5, \mathrm{O}_{3}$ or $\mathrm{NO}_{2}$ and FEV 1 for any of the pollutants in the subset of 2051 participants with regional air pollution and address-specific temperature data. Notably, only $\mathrm{O}_{3}$ was significantly associated with $\mathrm{FEV}_{1}$ in this subset: each $10 \mathrm{ppb}$ higher previous-day $\mathrm{O}_{3}$ was associated with a $19.7 \mathrm{~mL}$ lower FEV1 (95\% CI -37.2--2.2). When previous-day temperature was categorised as seasonal or unseasonably warm or cool (defined as $1 \mathrm{SD}$ higher or lower than the seasonal mean, respectively), there was a suggestion of effect modification $\left(p_{\text {interaction }}=0.08\right)$ for the association of PM2.5 with FEV1. Negative associations of PM2.5 with FEV1 were present on unseasonably warm days, but not unseasonably cool days, and a similar pattern was observed for the other pollutants (figure 3).

TABLE 3 Associations of temperature at home address and lung function

\begin{tabular}{llll} 
Temperature average & Unit & Difference in FEV1 $\mathrm{mL}$ & Difference in FVC $\mathrm{mL}$ \\
\hline 1-day & $5^{\circ} \mathrm{C}$ & $-16.7(-26.6--6.9)$ & $-13.4(-24.4--2.4)$ \\
2-day & $5^{\circ} \mathrm{C}$ & $-15.2(-26.2--4.2)$ & $-11.1(-23.4-1.3)$ \\
7-day & $5^{\circ} \mathrm{C}$ & $-19.8(-33.5--6.1)$ & $-16.2(-31.6--0.9)$ \\
\hline
\end{tabular}

Data are presented as mean difference $(95 \% \mathrm{Cl})$. Linear mixed models adjusted for participant sex, age, age $^{2}$, height, weight, asthma, smoking status, pack-years, household smoking, education, census tract median household income, season (as sine and cosine terms of the date), previous-day regional relative humidity and level of particles with a diameter of $<2.5 \mu \mathrm{m}$, examination 8 and cohort. FEV1: forced expiratory volume in $1 \mathrm{~s}$; FVC: forced vital capacity. 


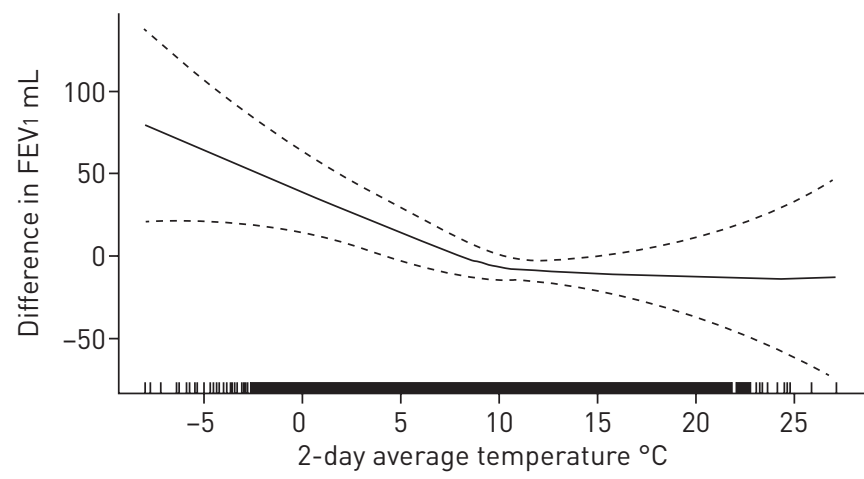

FIGURE 1 Two-day average temperature and forced expiratory volume in $1 \mathrm{~s}$ (FEV1). Generalised additive mixed model with penalised spline adjusted for age, sex, height, weight, smoking status and pack-years, second-hand smoke at home, asthma, education, census-level household income, cohort, examination 8 , season, previous-day relative humidity and level of particles with a diameter of $<2.5 \mu \mathrm{m}$. Degrees of freedom $=2.58$. Dotted lines represent $95 \% \mathrm{Cl}$. Black shading on the $\mathrm{x}$-axis indicates the density of observations.

\section{Discussion}

In this cohort of generally healthy adults residing in the Northeastern US, warmer temperature was associated with lower lung function, after controlling for season and other confounders. This negative relationship between temperature and lung function was steepest in the cooler temperature range $\left(<10^{\circ} \mathrm{C}\right)$, and present during winter and spring, but not summer. People with asthma and COPD had similar associations between temperature and lung function as those without these obstructive lung diseases.

Although we hypothesised that both colder and warmer outdoor temperatures would be associated with lower lung function in a non-linear pattern, our finding of a linear negative relationship between temperature and lung function is consistent with a growing number of studies that have found linear associations between higher daily outdoor temperatures and worse respiratory outcomes, including lung
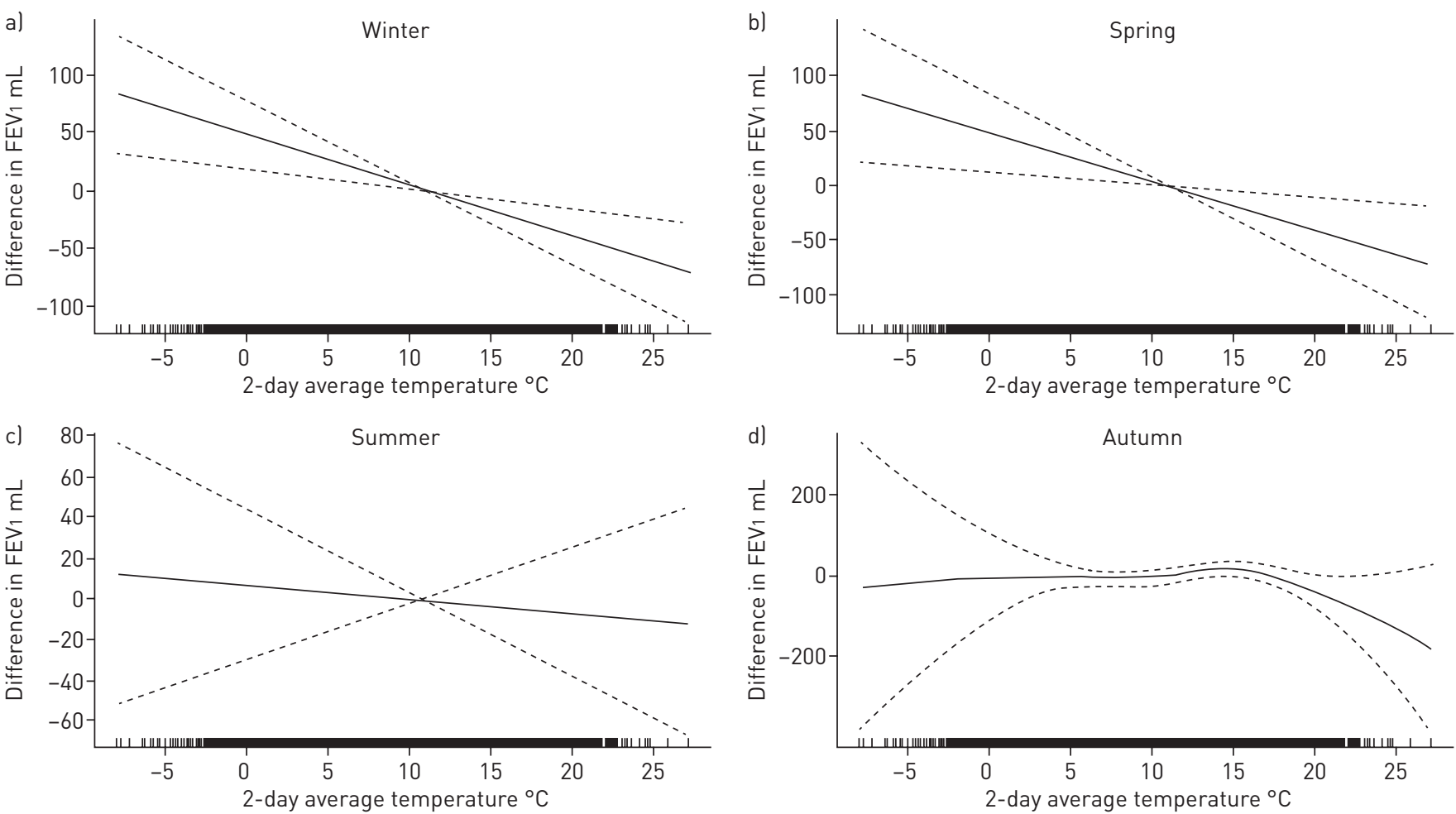

FIGURE 2 Two-day average temperature and forced expiratory volume in $1 \mathrm{~s}$ (FEV 1 ) by season. Generalised additive mixed model with penalised spline for the association between two-day temperature and FEV 1 in al winter, b) spring, c) summer and d) autumn, adjusted for age, sex, height, weight, smoking status and pack-years, second-hand smoke at home, asthma, education, census-level household income, cohort, examination 8 , season, previous-day relative humidity and level of particles with a diameter of $<2.5 \mu \mathrm{m}$. Dotted lines represent $95 \% \mathrm{Cl}$. Black shading along the $x$-axis indicates the density of observations. 
TABLE 4 Within-season associations of temperature at home address and FEV1

\begin{tabular}{lrrcc} 
Season & Unit & \multicolumn{3}{c}{ Difference in FEV $\mathbf{~ m L}$} \\
\cline { 3 - 5 } & & 1-day average temperature & 2-day average temperature & 7-day average temperature \\
\hline Winter & $5^{\circ} \mathrm{C}$ & $-28.5(-55.9--1.1)$ & $-23.5(-53.6-6.6)$ & $-53.5(-86.7--20.4)$ \\
Spring & $5^{\circ} \mathrm{C}$ & $-23.7(-44.8--2.5)$ & $-26.3(49.0--3.6)$ & $-31.5(-55.9--7.2)$ \\
Summer & $5^{\circ} \mathrm{C}$ & $10.0(-15.8-35.9)$ & $17.6(-13.7-48.9)$ & $27.3(-9.9-64.5)$ \\
Autumn & $5^{\circ} \mathrm{C}$ & $8.4(-12.5-29.3)$ & $11.7(-10.1-33.5)$ & $28.1(4.8-51.5)$
\end{tabular}

Data are presented as mean $\left(95 \%\right.$ CI). Linear mixed models adjusted for participant sex, age, age ${ }^{2}$, height, weight, asthma, smoking status, pack-years, household smoking, education, census tract median household income, previous-day regional relative humidity and level of particles with a diameter of $<2.5 \mu \mathrm{m}$, examination 8 and cohort. FEV1: forced expiratory volume in $1 \mathrm{~s}$.

function, respiratory symptoms and respiratory hospitalisation $[10,11,15,28,30]$. The Normative Aging Study of elderly men, also carried out in the temperate climate of the Northeastern US, found a negative association between increasing outdoor temperature (measured at a central urban monitor) averaged for the past 0-2 days and lung function [10]. This study did not detect effect modification by season, but the sample size was substantially smaller than our study (1103 versus 5896 participants). Two recent panel studies of healthy young adults in China found that higher temperatures were associated with lower lung function, measured by daily peak expiratory flow $[15,30]$. In one study in Beijing conducted in the months of April-November (temperature range $1-41^{\circ} \mathrm{C}$, mean $\sim 20^{\circ} \mathrm{C}$ ), each $5^{\circ} \mathrm{C}$ increase in same-day outdoor temperature, regardless of season, was associated with a $6.1 \mathrm{~L} \cdot \mathrm{min}^{-1}$ (95\% CI -11.1--1.1) lower evening peak expiratory flow rate [15]. An Australian study of urban asthmatic children also detected linear relationships between increasing temperature (for up to the past 3 days) and lower lung function, controlling for season and ambient pollution [11]. This study did not assess effect modification by season, but found that associations of higher temperature with lower lung function were greatest in the cooler more southern Australian cities than the northern subtropical city of Brisbane. Warmer outdoor temperatures have also been associated with lower lung function among cystic fibrosis patients [31].

The mechanism for this association of outdoor temperature with lung function is unclear and may not be mediated by the effect of temperature itself on the airways. It has been proposed that impaired thermoregulation in the setting of higher temperatures may trigger physiologic changes that ultimately reduce lung function [10], but such a mechanism is unlikely to explain our findings because we did not

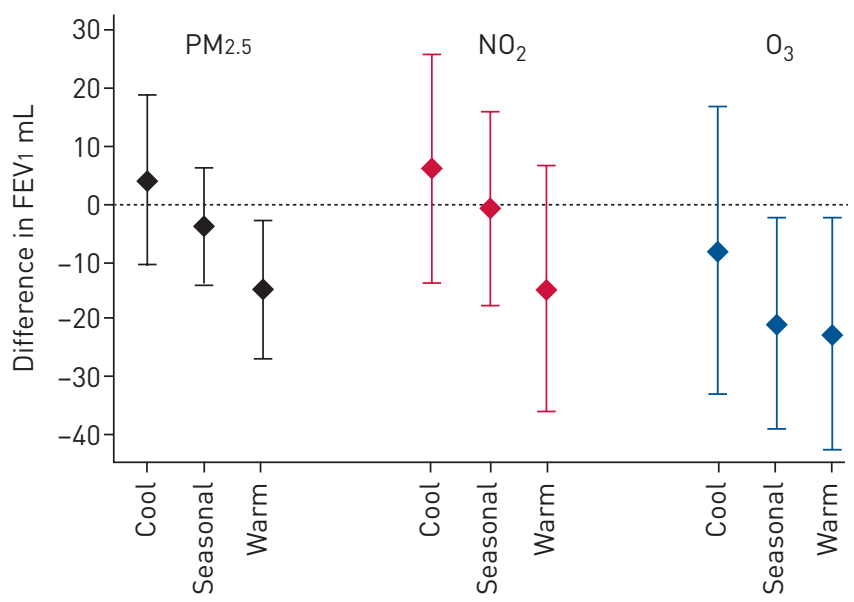

FIGURE 3 Previous-day pollution level and forced expiratory volume in $1 \mathrm{~s}$ (FEV1) based on previous-day temperature relative to seasonal mean. Particles with a diameter of $<2.5 \mu \mathrm{m}(\mathrm{PM} 2.5) \mathrm{scaled}$ per $5 \mu \mathrm{g} \cdot \mathrm{m}^{-3}$ (among 3047 observations), nitrogen dioxide $\left(\mathrm{NO}_{2}\right)$ scaled per $10 \mathrm{ppb}$ (among 3076 observations) and ozone $\left(\mathrm{O}_{3}\right.$ ) scaled per $10 \mathrm{ppb}$ lamong 1550 observations in monitoring season of April-September). Linear mixed models with an interaction term for previous-day temperature categorised as "cool" if $>1$ SD below mean temperature for season of test, "seasonal" if within 1 SD of mean temperature for season of test, and "warm" if $>1 \mathrm{SD}$ above mean temperature of season for test. All models were adjusted for participant sex, age, age ${ }^{2}$, height, weight, current asthma, smoking status, pack-years, household smoking, education, census tract median household income, cohort, date of examination, season (as sine and cosine terms), previous-day regional relative humidity and previous-day temperature at home address. Whiskers indicate the $95 \% \mathrm{Cl}$. 
detect an association with temperature during the hotter summer season. While this study did not measure daily behaviour, one possible unifying explanation is that participants spent, on average, more time outdoors (or with open windows) on warmer days during the cooler seasons. Outdoor exposures known to adversely affect lung function, such as air pollutants, environmental tobacco smoke, spring pollen and respiratory pathogens, may explain the lower lung function we observed in association with warmer temperatures. A recent National Health and Nutrition Examination Survey analysis found that lung function is on average lower in warmer parts of the USA: each $10^{\circ} \mathrm{F}\left(5.56^{\circ} \mathrm{C}\right)$ higher mean temperature was associated with $0.7 \%$ lower FEV1 \% pred [32]. Studies that have measured time spent outside the home have found that this time may influence lung function and respiratory symptoms. For example, a recent study of COPD patients found that higher outdoor temperature was associated with worse respiratory symptoms, and this association was only present on days when participants went outdoors [33]. We did not detect statistical evidence of differential susceptibility by asthma or COPD status, and the associations between temperature and lower lung function remained significant in these subgroups (supplementary table S1).

Mould is another temperature-dependent exposure that may affect lung function. Outdoor concentrations of mould spores tend to be higher on warmer days (even during the winter months for some species) [34, 35], and indoor levels of moulds such as Alternaria have been found to correlate highly with outdoor levels [36]. Higher exposure to fungal spores, including total fungal spores and Cladosporium species, has been associated with lower lung function in children [37, 38]. However, it is unclear how the daily fluctuation in mould spores of various species, influenced in part by temperature, affects lung function among healthy, mostly non-sensitised adults.

Some previous studies have suggested that higher temperatures and air pollution interact to increase mortality $[16,18,39,40]$ and reduce lung function $[10,15]$, though findings have not been consistent across studies [30, 41]. We did not find, as we had hypothesised, that previous-day temperature augmented associations of pollutants with lung function. Our analysis of temperature-pollution interactions had less statistical power than the main analysis of temperature because it was confined to a subset of study participants with address-specific temperature and local pollution data. In secondary analyses we observed a pattern of negative associations with pollutants, in particular PM2.5, following unusually warm days but not unusually cold days. This may be a consequence of greater pollution exposure on relatively warm days. More research is needed to determine if higher temperatures modify the effect of air pollutants on the lung.

This study has a number of limitations. Our study population consisted of predominantly white, middleand older-aged men and women residing in the Northeastern US, which limits generalisability to other groups. We had a maximum of two repeated measures of lung function for each participant and cannot infer causality from these associations. In our assessment of the interaction between temperature and pollution exposure, we assigned outdoor air pollution exposure measured within $40 \mathrm{~km}$ of each individual's home address to estimate individual exposure levels, which may not reflect actual exposures.

Our study also has a number of strengths. We examined moving averages of outdoor temperature and repeated measures of lung function in a well-characterised cohort of men and women, controlling for individual, neighbourhood and seasonal confounders. Other studies using stationary temperature monitors ignore potentially important differences that may influence temperature at individual residences, including urban heat islands, distance from water and amount of impermeable surface [19]. This analysis leveraged a validated spatiotemporal model of temperature using satellite surface temperature data [20] to more precisely estimate temperature at the home residence and examine how daily outdoor temperature relates to lung function among generally healthy adults.

In conclusion, we found that higher daily temperature was associated with lower lung function. These negative associations were present in winter and spring, but not in summer or autumn, and were present among people with and without asthma or COPD. We speculate that the apparent effect of warmer temperature on lung function may be a consequence of more time spent outdoors on warmer days, especially during the cooler seasons; however, we did not assess time spent outdoors in this study. It is important to understand associations between temperature and lung function because temperatures are increasing due to climate change [2]. Future research on the effect of temperature on respiratory health may consider how temperature affects activity patterns and outdoor exposure to pollutants and allergens, to distinguish health effects of temperature and other outdoor exposures.

Conflict of interest: M.B. Rice reports grants from the American Thoracic Society Foundation, American Lung Association and National Institutes of Environmental Health Sciences, during the conduct of the study; and she is the vice chair of the American Thoracic Society's Environmental Health Policy Committee. W. Li has nothing to disclose. 
E.H. Wilker reports grants from the National Institutes of Health and US Environmental Protection Agency, during the conduct of the study. D.R. Gold reports grants from the National Institutes of Health and US Environmental Protection Agency, during the conduct of the study. J. Schwartz has nothing to disclose. A. Zanobetti reports grants from the National Institutes of Health, US Environmental Protection Agency and Health Effect Institute, during the conduct of the study. P. Koutrakis reports a grant from US Environmental Protection Agency (RD-835872-01), during the conduct of the study. I. Kloog has nothing to disclose. G.R. Washko reports grants from the National Institutes of Health and BTG Interventional Medicine, grants and other support from Boehringer Ingelheim and Janssen Pharmaceuticals, other support from Genentech, Quantitative Imaging Solutions, PulmonX, Regeneron, ModoSpira, Toshiba and GlaxoSmithKline, outside the submitted work; G.R. Washko's spouse works for Biogen, which is focused on developing therapies for fibrotic lung disease. G.T. O'Connor reports personal fees from AstraZeneca and grants from Janssen Pharmaceuticals, outside the submitted work. M.A. Mittleman reports grants from the National Institutes of Health and US Environmental Protection Agency, during the conduct of the study.

Support statement: This work was supported by the American Lung Association, American Thoracic Society, National Heart, Lung, and Blood Institute (grant number: N01-HC-2519), National Institute of Environmental Health Sciences (grant numbers: K23ES026204 and P30ES000002) and the US Environmental Protection Agency (grant number: $\mathrm{RD}$-835872). Funding information for this article has been deposited with the Crossref Funder Registry.

\section{References}

1 Rice MB, Thurston GD, Balmes JR, et al. Climate change a global threat to cardiopulmonary health. Am J Respir Crit Care Med 2014; 189: 512-519.

2 Bayram H, Bauer AK, Abdalati W, et al. Environment, global climate change, and cardiopulmonary health. Am J Respir Crit Care Med 2017; 195: 718-724.

3 Michelozzi P, Accetta G, De Sario M, et al. High temperature and hospitalizations for cardiovascular and respiratory causes in 12 European cities. Am J Respir Crit Care Med 2009; 179: 383-389.

4 Fouillet A, Rey G, Laurent F, et al. Excess mortality related to the August 2003 heat wave in France. Int Arch Occup Environ Health 2006; 80: 16-24.

5 Song X, Wang S, Li T, et al. The impact of heat waves and cold spells on respiratory emergency department visits in Beijing, China. Sci Total Environ 2017; 615: 1499-1505.

6 Mireku N, Wang Y, Ager J, et al. Changes in weather and the effects on pediatric asthma exacerbations. Ann Allergy Asthma Immunol 2009; 103: 220-224.

7 Berk JL, Lenner KA, McFadden ER. Cold-induced bronchoconstriction: role of cutaneous reflexes versus direct airway effects. J Appl Physiol 1987; 63: 659-664.

8 Hayes D, Collins PB, Khosravi M, et al. Bronchoconstriction triggered by breathing hot humid air in patients with asthma: role of cholinergic reflex. Am J Respir Crit Care Med 2012; 185: 1190-1196.

9 Aitken ML, Marini JJ. Effect of heat delivery and extraction on airway conductance in normal and in asthmatic subjects. Am Rev Respir Dis 1985; 131: 357-361.

10 Lepeule J, Litonjua AA, Gasparrini A, et al. Lung function association with outdoor temperature and relative humidity and its interaction with air pollution in the elderly. Environ Res 2018; 165: 110-117.

11 Li S, Baker PJ, Jalaludin BB, et al. Ambient temperature and lung function in children with asthma in Australia. Eur Respir J 2014; 43: 1059-1066.

12 Rice MB, Ljungman PL, Wilker EH, et al. Short-term exposure to air pollution and lung function in the Framingham Heart Study. Am J Respir Crit Care Med 2013; 188: 1351-1357.

13 Paulin L, Hansel N. Particulate air pollution and impaired lung function. F1000Research 2016: 5.

14 Brunekreef B, Dockery DW, Krzyzanowski M. Epidemiologic studies on short-term effects of low levels of major ambient air pollution components. Environ Health Perspect 1995; 103: Suppl. 2, 3-13.

$15 \mathrm{Wu} \mathrm{S}$, Deng F, Hao Y, et al. Fine particulate matter, temperature, and lung function in healthy adults: findings from the HVNR study. Chemosphere 2014; 108: 168-174.

16 Katsouyanni K, Pantazopoulou A, Touloumi G, et al. Evidence for interaction between air pollution and high temperature in the causation of excess mortality. Arch Environ Health 1993; 48: 235-242.

17 Analitis A, Katsouyanni K, Biggeri A, et al. Effects of cold weather on mortality: results from 15 European cities within the PHEWE project. Am J Epidemiol 2008; 168: 1397-1408.

18 Qian Z, He Q, Lin H-M, et al. High temperatures enhanced acute mortality effects of ambient particle pollution in the "oven" city of Wuhan, China. Environ Health Perspect 2008; 116: 1172-1178.

19 Kloog I, Chudnovsky A, Koutrakis P, et al. Temporal and spatial assessments of minimum air temperature using satellite surface temperature measurements in Massachusetts, USA. Sci Total Environ 2012; 432: 85-92.

20 Mehta AJ, Kloog I, Zanobetti A, et al. Associations between changes in city and address specific temperature and QT interval-the VA Normative Aging Study. PLoS One 2014; 9: e106258.

21 Lee M, Nordio F, Zanobetti A, et al. Acclimatization across space and time in the effects of temperature on mortality: a time-series analysis. Environ Health 2014; 13: 89 .

22 Kannel WB, Feinleib M, McNamara PM, et al. An investigation of coronary heart disease in families. The Framingham Offspring Study. Am J Epidemiol 1979; 110: 281-290.

23 Splansky GL, Corey D, Yang Q, et al. The Third Generation Cohort of the National Heart, Lung, and Blood Institute's Framingham Heart Study: design, recruitment, and initial examination. Am J Epidemiol 2007; 165: $1328-1335$.

24 Kloog I, Nordio F, Coull BA, et al. Predicting spatiotemporal mean air temperature using MODIS satellite surface temperature measurements across the Northeastern USA. Remote Sens Environ 2014; 150: 132-139.

25 Di Q, Dai L, Wang Y, et al. Association of short-term exposure to air pollution with mortality in older adults. JAMA 2017; 318: 2446-2456.

26 Standardization of Spirometry, 1994 Update. American Thoracic Society. Am J Respir Crit Care Med 1995; 152: $1107-1136$.

27 Rice MB, Ljungman PL, Wilker EH, et al. Long-term exposure to traffic emissions and fine particulate matter and lung function decline in the Framingham Heart Study. Am J Respir Crit Care Med 2015; 191: 656-664. 
28 Anderson GB, Dominici F, Wang Y, et al. Heat-related emergency hospitalizations for respiratory diseases in the Medicare population. Am J Respir Crit Care Med 2013; 187: 1098-1103.

29 Ito K, Weinberger KR, Robinson GS, et al. The associations between daily spring pollen counts, over-the-counter allergy medication sales, and asthma syndrome emergency department visits in New York City, 2002-2012. Environ Health 2015; 14: 71.

30 Zhang $\mathrm{Y}, \mathrm{He} \mathrm{M}, \mathrm{Wu} \mathrm{S}$, et al. Short-term effects of fine particulate matter and temperature on lung function among healthy college students in Wuhan, China. Int J Environ Res Public Health 2015; 12: 7777-7793.

31 Collaco JM, McGready J, Green DM, et al. Effect of temperature on cystic fibrosis lung disease and infections: a replicated cohort study. PLoS One 2011; 6: e27784.

32 Collaco JM, Appel LJ, McGready J, et al. The relationship of lung function with ambient temperature. PLoS One 2018; 13: e0191409.

33 McCormack MC, Belli AJ, Waugh D, et al. Respiratory effects of indoor heat and the interaction with air pollution in chronic obstructive pulmonary disease. Ann Am Thorac Soc 2016; 13: 2125-2131.

34 Núñez A, de Paz G A, Rastrojo A, et al. Monitoring of airborne biological particles in outdoor atmosphere. Part 1: Importance, variability and ratios. Int Microbiol 2016; 19: 1-13.

35 Recio M, del Trigo MM, Docampo S, et al. Analysis of the predicting variables for daily and weekly fluctuations of two airborne fungal spores: Alternaria and Cladosporium. Int J Biometeorol 2012; 56: 983-991.

36 O'Connor GT, Walter M, Mitchell H, et al. Airborne fungi in the homes of children with asthma in low-income urban communities: the Inner-City Asthma Study. J Allergy Clin Immunol 2004; 114: 599-606.

37 Chen B-Y, Jasmine Chao $\mathrm{H}, \mathrm{Wu} \mathrm{C}$, et al. High ambient Cladosporium spores were associated with reduced lung function in schoolchildren in a longitudinal study. Sci Total Environ 2014; 481: 370-376.

38 Chen B-Y, Chao HJ, Chan C-C, et al. Effects of ambient particulate matter and fungal spores on lung function in schoolchildren. Pediatrics 2011; 127: e690-e698.

39 Analitis A, Michelozzi P, D'Ippoliti D, et al. Effects of heat waves on mortality: effect modification and confounding by air pollutants. Epidemiology 2014; 25: 15-22.

40 Ren C, Williams GM, Morawska L, et al. Ozone modifies associations between temperature and cardiovascular mortality: analysis of the NMMAPS data. Occup Environ Med 2008; 65: 255-260.

41 Stafoggia M, Schwartz J, Forastiere F, et al. Does temperature modify the association between air pollution and mortality? A multicity case-crossover analysis in Italy. Am J Epidemiol 2008; 167: 1476-1485. 